and gaseous phases in turn. After an introduction to the general physical characteristics of soils and basic properties of water, the solid phase of soil is studied through a consideration of particle size distributions and specific surface areas, the properties of clays, and structure and aggregation. The concept of soil water potential is carefully developed and used in a consideration of both saturated and unsaturated hydraulic conductivity and the movement of solutes. The roles of diffusion and respiratory activity in determining the composition of the soil atmosphere are considered and this leads naturally to a chapter on heat flow and temperature. Finally, soil strength, consistency and compaction are discussed.

The author introduces essential physics where appropriate and is thorough without being overly mathematical. Thus care has been taken to use both one- and threedimensional forms of flow equations. Developments of theoretical aspects describing basic processes are complemented by discussion of both laboratory and field methods of measuring important parameters. Except, perhaps, for the lack of any coverage of the soil-plant-atmosphere continuum and erosion, this text alone should cover most undergraduate courses.

Applications . . continues the discussion, paying particular attention to the management of the soil environment and the field-water cycle. Thus infiltration, drainage, irrigation, evaporation and soil moisture uptake by plants are considered, drawing on the basic principles introduced in the companion volume. These themes are elaborated in a second section consisting of five chapters by invited authors who cover further aspects of the field-water cycle and the problems of studying soil heterogeneity. These contributions dovetail well with the earlier section and give a useful insight into some of the more advanced realms of soil physics.

These two books provide a modern, clear and concise introduction to soil physics. They are international in style and content, drawing examples from a wide range of situations. Unfortunately the cgs system of units is used, though the metric equivalents are often given (however, the Pascal is not introduced when considering soil water potential). Whilst the texts do introduce an appreciable amount of mathematics, they should not prove too difficult for the careful student and understanding is aided by the excellent sample problems at the end of each chapter. Over 400 references (up to 1980) are given at the end of each volume, and provide a good starting point for further work.

Together, the two volumes represent an admirable textbook for undergraduates. They should certainly be in every library covering soil science.

David Rimmer and Michael Adey are Lecturers in the Department of Soil Science at the University of Newcastle upon Tyne.

\title{
Dirty work at the crossroads?
}

\section{M.J. Kirkby}

Soils and Landforms: An Integration of Geomorphology and Pedology. By A.J. Gerrard. Pp.219. Hbk ISBN 0-04551048-2; pbk ISBN 0-04-551049-0. (George Allen \& Unwin: 1981.) Hbk £15, \$35; pbk £7.95, \$16.95.

SoIL science and geomorphology have borrowed from one another throughout their joint histories and, as with other disciplines, the relationship has been very fruitful. Areas of mutual interaction have, however, largely relied on the static properties of soil or sediment, while understanding of process dynamics has followed rather divergent paths in the two disciplines. Pedologists have tended to concentrate on the chemistry, physics and biology of the soil, mainly at a micro-scale; while geomorphologists have attempted to understand sediment and solute transfers, generally at a macroscopic to world-wide scale.

One very important area of common ground has, I think, been surprisingly neglected. At its simplest, it springs from the obvious fact that contemporary soils are the very materials which are moved downhill by current landform processes. It follows that the physical and chemical processes by which landforms and soils evolve are substantially identical. To develop this theme - and there are signs that it is being increasingly developed there is an urgent need to collate existing concepts and data; to translate concepts between the two disciplines; and to re-think many of our approaches in a new idiom.

John Gerrard's book makes a worthwhile contribution to the first of these three aims, by bringing together work on soil formation, on soil movement and removal, on hillside hydrology and on the catena concept which must be central to any integrative work. In reviewing this material there is however little evidence of fresh insights or of the author's own syntheses, so that little headway is made in translating concepts or adding to them.

About half of the book then proceeds to consider soils on the basis of the landforms on which they are formed, including soils on erosion surfaces, flood and coastal plains, and glacial deposits. In this section, there is the focus on landforms which might

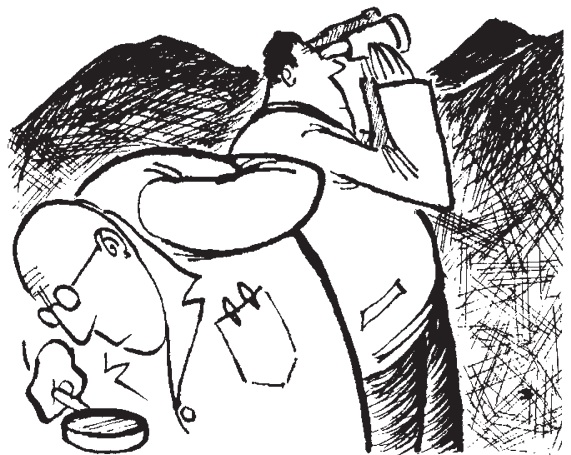

be expected from the title, but not enough emphasis on the links with solution and other geomorphological processes. The final chapter, "A Pedogeomorphic Synthesis", is very brief and summarizes the general timidity in approaching any conceptual development. With other recent books, such as R.V. Ruhe's Geomorphology (Houghton Mifflin, 1975) and P.W. Birkeland's Pedology, Weathering and Geomorphological Research (Oxford University Press, 1974), it will nonetheless be of help to those wishing to begin work on a topic which is, and should be, ripe for considerable development.

M.J. Kirkby is Professor of Physical Geography at The University of Leeds.

\section{Back to the land}

\section{D.L. Dineley}

The Stratigraphy of the British Isles, 2nd Edn. By Dorothy H. Rayner. Pp.460. Hbk ISBN 0-521-23452-2; pbk ISBN 0521-29961-6. (Cambridge University Press: 1981.) Hbk $£ 32.50, \$ 59.50$; pbk $£ 12.50$. The Structure of the British Isles, 2nd Edn. By J.G.C. Anderson and T.R. Owen. Pp.251. Hbk ISBN 0-08-023998-6; pbk ISBN 0-08-023997-8. (Pergamon: 1980.) Hbk £13.75, \$32; pbk £5.95, \$14.50. Methods in Field Geology. By Frank Moseley. Pp.211. Hbk ISBN 0-71671293-8; pbk ISBN 0-7167-1294-6. (W.H. Freeman: 1981.) Hbk $\$ 29.95, £ 12.95$; pbk $£ 6.95, \$ 14.95$

Good "standard" geological texts abound; trying to revise them to keep abreast of new facts and ideas is a daunting task for any author. In this trio, the stratigraphy and structure of the British Isles are described in two second editions, while the third text shows how basic field studies may be carried out. Whilst the influence of new hypotheses upon the Rayner and the Anderson and Owen books is rather small, Moseley's book is another matter altogether; new ideas have their place there, and in style and content it is very welcome.

Since the first edition of Rayner appeared in 1967, the impact of plate tectonic theory upon stratigraphy has prompted intriguing new scenarios explaining the geological evolution of the British Isles and western Europe. Dynamic stratigraphy has replaced the classical "static" listing of strata; attention has swung to the relationships between sedimentation, igneous activity and tectonism. The first edition was a clear account of the strata found in these islands. The second is 